\title{
Effective safe technique for surgical canalization of congenital aural atresia with the same session reconstruction of the meatus and TM by split thickness graft (Autograft)
}

\author{
Mohammed Saad Hasaballah, Ahmed Abdelmoneim Teaima* (1D, Peter Milad and Ossama Mustafa Mady
}

\begin{abstract}
Background: This case series study is to evaluate the results of our technique for correction of congenital aural atresia. Seventeen patients were done from 2015 till 2018, 4 cases bilateral and 13 unilateral. Surgical canalization of congenital aural atresia with the same session reconstruction of the meatus and TM by split thickness graft (Autograft) was done. Follow-up is done weekly for 3 months then every 2 weeks for another 3 months, till we establish the formation of EAC. All cases were followed up for at least 1 year.

Results: All patients have now established skin limned external canal. There is no facial nerve or dural or sigmoid injuries. Only one case TMJ was exposed during the surgical procedure. One case had postauricular wound gapping and another one was complicated after 1 year by stenosis. All patients improved subjectively in speech and language postoperatively except one case who has autism and still undertreatment.

Conclusion: Congenital aural atresia is a challenging surgery. Surgical canalization with the same session grafting of the drum and the formed cavity by split thickness skin graft is effective with minimal minute rate of complications and recurrence.
\end{abstract}

Keywords: Aural atresia, Ossicles, Aural atresioplasty

\section{Background}

Congenital aural atresia is not an uncommon disorder. It represents 1 in 10,000 live births [1]. It involves abnormal development of the first pharyngeal cleft. It results in varied degrees of malformation that affects the ossicles, middle ear space, tympanic membrane (TM), bony and cartilaginous external canal, and pinna [2]. The most common associated ossicular deformity is fused or amalgamated ossicular chain. Congenital aural atresia repair is a challenging surgery. Surgical anatomy

\footnotetext{
* Correspondence: a.teaima@med.asu.edu.eg

Department of Otorhinolaryngology, Faculty of Medicine, Ain Shams University, Cairo, Egypt
}

\section{Springer Open}

(c) The Author(s). 2020 Open Access This article is licensed under a Creative Commons Attribution 4.0 International License which permits use, sharing, adaptation, distribution and reproduction in any medium or format, as long as you give appropriate credit to the original author(s) and the source, provide a link to the Creative Commons licence, and indicate if changes were made. The images or other third party material in this article are included in the article's Creative Commons licence, unless indicated otherwise in a credit line to the material. If material is not included in the article's Creative Commons licence and your intended use is not permitted by statutory regulation or exceeds the permitted use, you will need to obtain permission directly from the copyright holder. To view a copy of this licence, visit http://creativecommons.org/licenses/by/4.0/.

of the facial nerve, mastoid, middle ear, and inner ear as well as their congenital variations is mandatory for this surgery [3]. Atresioplasty surgery is done for the creation of a patent EAC and meatus in addition to providing hearing either by anterior approach or transmastoid approach [4]. Many grading systems and surgical approaches were modified in the past 40 years by otologists like De la Cruz and Jahrsdoerfer to obtain better outcomes [5]. Several informative retrospective case series evaluating the procedures and its complications have been reported [6]. Still, atresiaplasty results remain a topic of interest. There are two opinions either to do canalization before auriculoplasty or to do staged otoplasty before surgical canalization. Here, we present our 
case series of correction of congenital aural atresia and we think this technique may be better and efficient by results and follow-up.

\section{Methods}

This study was done in our otorhinolaryngology department from January 2015 to December 2018. Seventeen patients were done from 2015 till 2018, 4 cases bilateral, 13 unilateral, 8 females, and 9 males. The average age is 6.5 years old. All patients were not operated before either for canalization or cosmetically. All patients underwent audiological evaluation, CT scan temporal bone non-contrasted thin cut ( $2 \mathrm{~mm}$ cuts) coronal, and axial cuts. We preceded to operate patients with nearly mature middle ear cleft space. Also, most of our cases carry more or less normal courses of temporal bone vital structures as facial nerve, internal carotid artery, and middle fossa dural levels. We excluded anatomical anomalies of important structures, and also, we excluded cases with marked hypoplastic middle ear cleft structures. Unilateral cases were operated for this side, while bilateral cases were also operated unilaterally first for the more mature ear anatomically and functionally. All cases were operated by the same technique and surgeons. Follow-up is done weekly for 3 months then every 2 weeks for another 3 months, till we establish formation of EAC. Every visit, we exchange the ear pack using merocel sponge soaked with antibiotic ointment. The follow-up continued till we established adequate epithelialized EAC with easily visible new TM and dry ear. This usually occurs within 6 months to 1 year. All cases were followed up for at least 1 year.

\section{Technique}

1- First step study CT scan well: degree and nature of atresia, mastoid and antrum pneumatization, position of dura, facial nerve, carotid artery, and sigmoid sinus (Fig. 1)
2- After anesthesia: we examine the patient to determine the site of TMJ, zygomatic arch, mastoid tip level, and atretic segment. Also, we determine the expected site of the future external auditory canal in relation to the auricle. If it will be in front of the deformed auricle, it will be good. If it will be behind the deformed auricle, we will plan additional procedure to transfer the auricle behind to fashion the future EAC opening in front of the deformed auricle. This will be done by removal of strip of skin vertical over the mastoid then at the end of surgery when we close the postauricular incision; we do it under tension. This will pull the auricle posteriorly.

3- Postauricular incision and making mucoperiosteal flap anteriorly based and expose the mastoid and the atretic segment to start drilling. Exposure will be from supramastoid crest superiorly to mastoid tip inferiorly, and from TMJ and root of zygoma anteriorly to area retromastoid posteriorly.

4- Start to drill the mastoid in the following strict sequence:

a- Start to do drilling in the superficial mastoid air cells

b- Start to skeletonize dural plate and sinus plate of the mastoid till you reach the antrum air cells

c- From the sinodural angle, we start to drill anteriorly with the dural line and very near to the dural plate to reach the antrum air cell.

d- Start to remove the outer antral bone anteriorly and superiorly directed toward attic, and drilling must be very close to dural plate till we reach the ossicular chain which may be normal or more frequently fused

e- At this moment, we start to drill superficial to ossicular chain and inferiorly in direction till we complete removing the atretic segment and exposing stapes and oval window if they are not deformed.

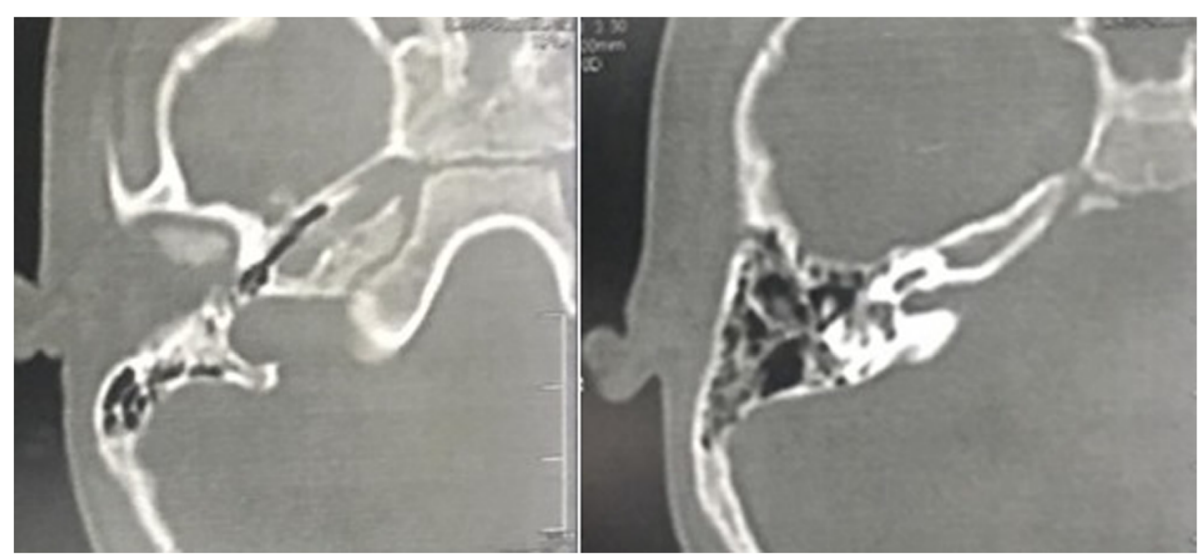

Fig. 1 Radiological assessment 
f- Putting temporalis fascia graft over the ossicular chain then put another layer of split thickness skin graft

g- Then start to fashion suitable opening of the skin over the formed bony cavity. This opening must be anterior to the deformed auricle. This is achieved by removing strip of skin from postauricular area, and when we resuture the postauricular incision, it will pull the auricle posteriorly and the skin opening will overlap the bony cavity (Fig. 2).

h- Finally, we harvest split thickness skin graft from non-hairy area in the postauricular area (Fig. 3) or from the thigh. This skin graft will be diverted to outside to be sutured to the edges of the skin openings. Then we support the skin graft of the external canal by silastic sheet. Then we put pieces of gel foam inside the cavity and external canal and closure.

\section{Results (Figs. 4 and 5)}

Our results were complete success to create adequate epithelized meatus in all our cases except in one case; the patient had restenosis (4.6\%) within 3 months and she needed surgery. This occurs due to recurrent local infection as she was hyperactive and had bad compliance to ear packs and remove it. No complications occurred during surgery neither facial nerve injury nor dural or sigmoid injury. Only one case TMJ was exposed during the surgical procedure while was complicated postoperatively by pain and tenderness in the joint. This case was treated by hot foments and analgesic for 1 week.

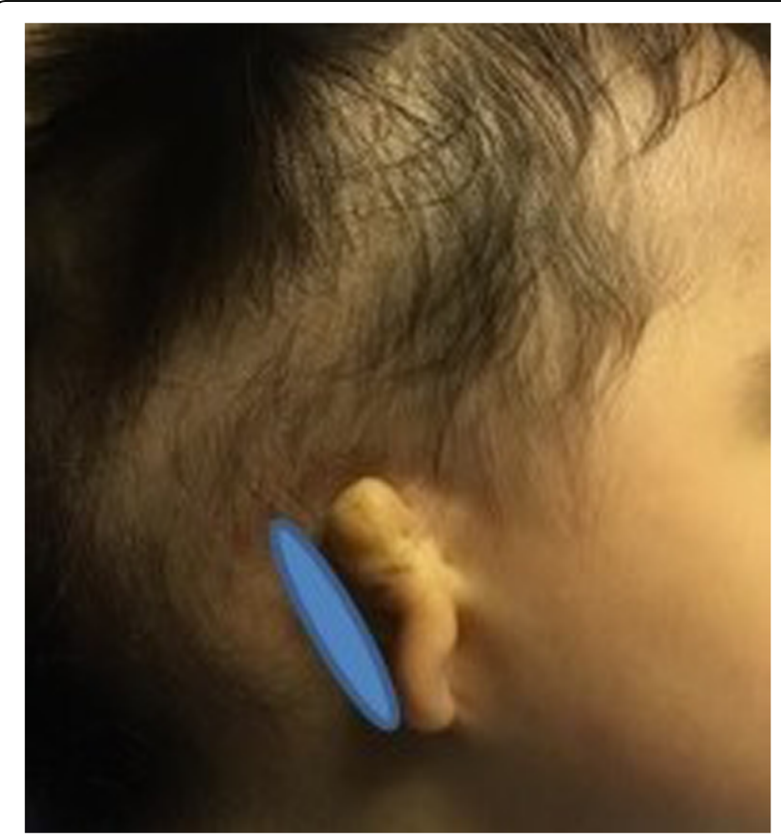

Fig. 2 The part of skin removed in postauricular area

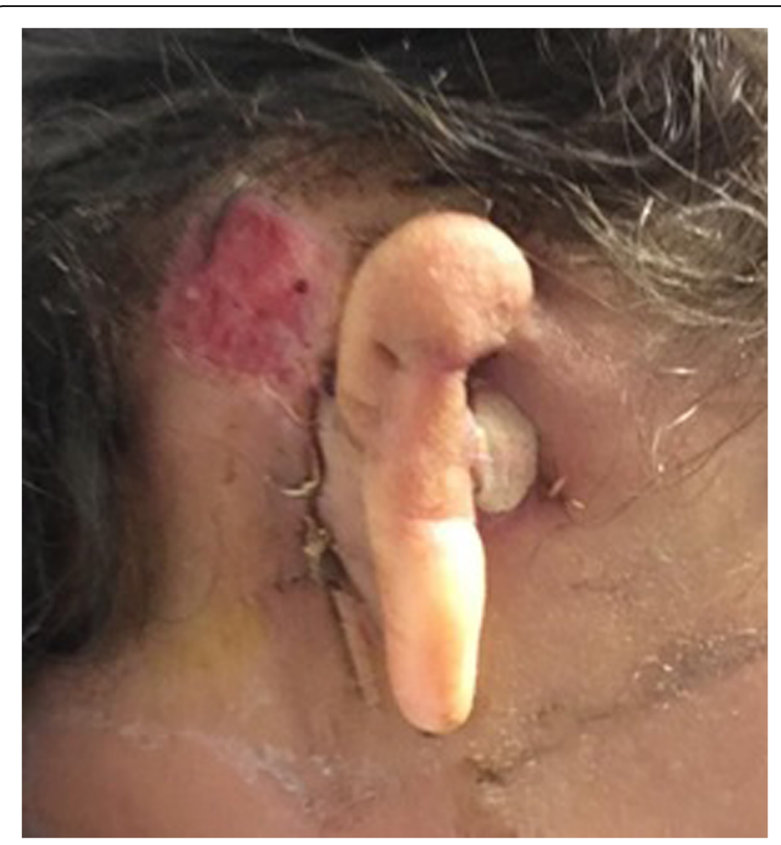

Fig. 3 Postoperative image

One case was complicated postoperatively by gapping of postauricular wound and was treated by secondary suturing.

All patients were conductive pattern of hearing loss with average $50 \mathrm{~dB}$ air-bone gap (ABG), and although the postoperatively average ABG $35 \mathrm{~dB}$, all patients improved subjectively in speech and language postoperatively except one case who has autism and still under treatment.

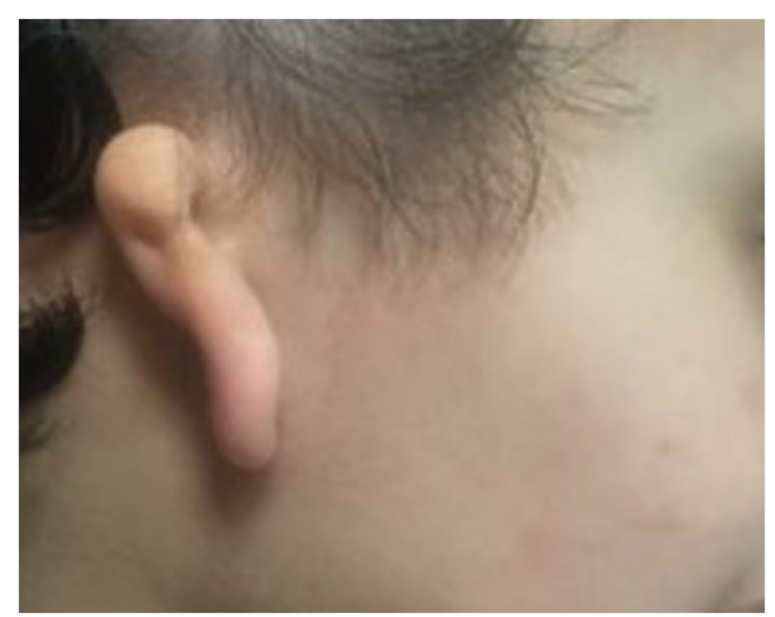

Fig. 4 Preoperative 


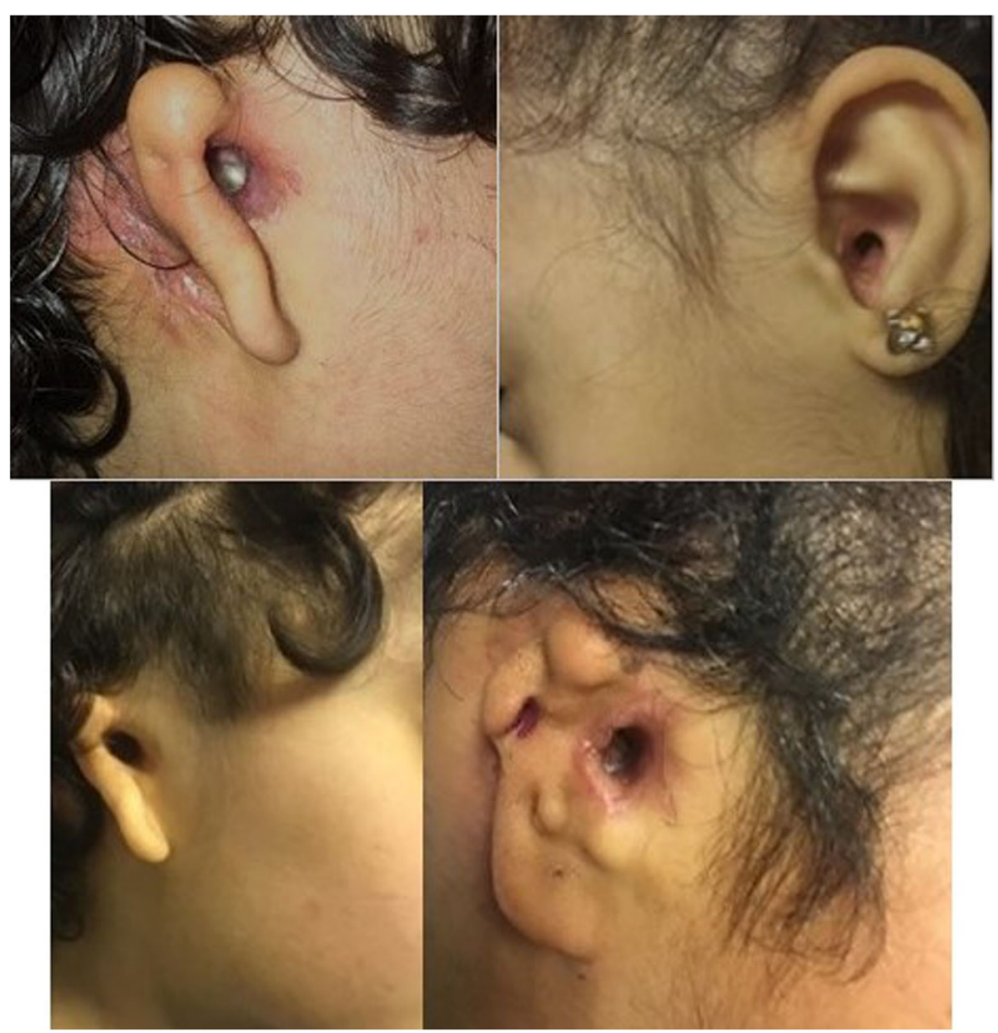

Fig. 5 Postoperative results

\section{Discussion}

Cases with congenital meatal atresia are very challenging. To gain good results, you must counsel the family that the treatment and follow-up will take long time and need effort.

You must choose good candidates on basis of imaging and audiological assessment. Very meticulous and very cautious surgical steps are needed to avoid intraoperative complications. Good grafting of the tympanic membrane and the cavity of the canal by split thickness skin graft is mandatory. Repeated ear packing by any method for 6-12 months is mandatory to prevent restenosis.

In Egypt, we recommend canalization because BAHA is so costly and it is not affordable in most of cases. Also, we do canalization preceding auricular reconstruction in patients with minute auricular deformity.

\section{Conclusion}

Congenital aural atresia is a challenging surgery. Surgical canalization with the same session grafting of the drum and the formed cavity by split thickness skin graft is effective with minimal minute rate of complications and recurrence.

\section{Abbreviations}

TM: Tympanic membrane; EAC: External auditory canal;

TMJ: Temporomandibular joint; ABG: Air-bone gap; BAHA: Bone-anchored hearing aid

\section{Acknowledgements}

The authors have no acknowledgements to disclose.

\section{Authors' contributions}

$\mathrm{MH}$ has done the surgeries assisted with PM and both collected the patients. OM interpreted the data and reviewed the literature. AT has prepared the manuscript with the help of the authors and will be the corresponding author. All authors have read and approved the manuscript.

\section{Funding}

The authors have no funding to disclose.

\section{Availability of data and materials}

The datasets used and/or analyzed during the current study are available from the corresponding author on reasonable request.

\section{Ethics approval and consent to participate}

The study involves human participants. All procedures performed in studies involving human participants were approved by Ain Shams University, Faculty of Medicine Ethics Review Board. Consents for participation in the study were taken from patients' parents.

\section{Consent for publication}

Consents for publication were taken from patients' parents.

\section{Competing interests}

The authors have no competing interests to disclose.

Received: 23 March 2020 Accepted: 11 June 2020

Published online: 17 August 2020

\section{References}

1. De la Cruz A, Linthicum FH, Luxford WM (1985) Congenital atresia of external auditory canal. Laryngoscope 95:421-427 
2. Bellucci RJ (1981) Congenital aural malformations: diagnosis and treatment. Otolaryngol Clin North Am. 14(1):95-124

3. Alarcon AD, Choo DI (2007) Controversies in aural atresia repair. Curr opin Otolaryngol Head Neck Surg 15:310-314

4. Shih L, Crabtree JA (1993) Long-term surgical results for congenital aural atresia. Laryngoscope 103:1097-1102

5. Jahrsdoerfer RA (2003) Surgery for congenital aural atresia. In: Glasscock ME, Gulya AJ (eds) Glasscock-Shambaugh surgery of the ear, 5th edn. BC Decker, Hamilton, pp 389-399

6. Edfeldt L, Strömbäck K (2015) Surgical treatment of congenital aural atresia-is it still justified? Acta Otolaryngol. 135(3):226-232

\section{Publisher's Note}

Springer Nature remains neutral with regard to jurisdictional claims in published maps and institutional affiliations.

\section{Submit your manuscript to a SpringerOpen ${ }^{\circ}$ journal and benefit from:}

- Convenient online submission

- Rigorous peer review

- Open access: articles freely available online

- High visibility within the field

- Retaining the copyright to your article 